УДК 577

DOI: 10.33184/spbgb-2021-09-21.10

\title{
Морфогенез in vitro в каллусах ячменя: влияние флуридона
}

\author{
() И.Р. Галин, О.А. Сельдимирова*
}

Уфомский Институт биологии УФИЦ РАН

Россия, Республика Башкортостан, 450054 г. Уфра, проспект Октябряб 69

*E-mail: o_seldimirova@mail.ru

С использованием методов световой микроскопии и твердофразного иммуноферментного анализа изучено влияние ингибитора синтеза эндогенной АБК фрлуридона на морфогенез in vitro и содержание эндогенных АБК и ИУК в каллусах дефицитного по АБК мутанта ячменя AZ34 и его родительского сорта Steptoe. Установлено, что к 4-й неделе культивирования in vitro на среде с добавлением фрлуридона наблюдалось значительное повышение содержания ИУК на фоне снижения содержания АБК по сравнению с контролем. Изучено влияние фрлуридона на протекание путей морфогенеза in vitro в каллусах изучаемых генотипов. Сделан вывод о важной роли АБК в процессе эмбриоидогенеза in vitro.

Ключевые слова: ячмень, Hordeum vulgare L., культура in vitro, каллус, фрлуридон, АБК, ИУК.

Установлено, что фритогормональный фактор - ключевой при культивировании in vitro растительных тканей и органов, в том числе в каллусных культурах $[17,23,25]$. Один из путей морфогенеза in vitro, реализуемых в каллусах, - эмбриоидогенез - формирование зародышеподобных биполярных структур из клетки/групп клеток эмбриоидогенных каллусов в ответ на экзогенные и/или эндогенные сигналы $[11,14,15]$.

В исследованиях эмбриоидогенеза in vitro большое внимание уделяется ауксинам и цитокининам, как основным регуляторам этого процесса $[11,13,17,23]$, в то время как участию АБК в регуляции эмбриоидогенеза in vitro уделяется гораздо меньше внимания. Основная масса работ направлена на изучение влияния экзогенной АБК на индукцию формирования и развития эмбриоидов in vitro. Эти работы главным образом посвящены исследованиям прямого эмбриоидогенеза in vitro, при котором эмбриоиды формируются непосредственно из клеток экспланта, минуя стадию каллуса. Полученные данные, как правило, достаточно противоречивы [обзоры: 4, 18]. Данные же об участии в эмбриоидогенезе in vitro эндогенной АБК малочисленны, и особенно это касается злаков $[19,21]$. Кроме того, данные о взаимодействии АБК и ИУК, а также о влиянии ингибиторов синтеза АБК на процессы эмбриоидогенеза in vitro также единичны $[8,20,24]$.

В связи с этим цель работы состояла в изучении влияния ингибитора синтеза эндогенной АБК - фрлуридона на морфогенез in vitro, в том числе эмбриоидогенез, и содержание эндогенных АБК и ИУК в каллусах ячменя.

Объектами исследования послужили ячмень сорта Steptoe и его АБК-дефицитный мутант AZ34. Каллусы получали из незрелых зародышей на 13-15 сутки после массового цветения, как описано [2]. Для культивирования использовали среду МС, дополненную $2.0 \mathrm{мг/л} \mathrm{2,4-Д,} 0.5$ мг/л 6-БАП и $12.5 \mathrm{mг/л} \mathrm{CuSO4} \mathrm{x} \mathrm{12H2O} \mathrm{(контроль),} \mathrm{Для} \mathrm{изучения} \mathrm{вли-}$ яния ингибитора синтеза эндогенной АБК в вышеописанную среду добавляли 100 мг/л 
фрлуридона [6]. Каллусы культивировали в течение 4 недель в темноте, при $26^{\circ} \mathrm{C}$. Для индукции эмбриоидогенеза каллусы переносили на среду МС без добавления регуляторов роста. Для оценки содержания гормонов использовали каллусы через 1 и 4 недели культивирования in vitro на среде с регуляторами роста, для гистологического анализ - через 1 неделю культивирования in vitro на среде без регуляторов роста. Использовали метод твердофазного иммуноферментного анализа в модификации [26] и методы световой микроскопии [3]. Препараты просматривали и документировали с использованием микроскопа проходящего света Axio Imager (Carl Zeiss, Jena, Германия), оснащенного цифровой камерой AxioCam MRc5 (Carl Zeiss, Jena, Германия). Статистическую обработку полученных результатов проводили с применением программы Microsoft Office Excel 2010.

После 1-й недели культивирования in vitro уровень АБК как у AZ34, так и у Steptoe был выше по сравнению с 4-й неделей in vitro на обоих вариантах питательных сред (рис. 1). Эти данные согласуются с полученными нами ранее результатами по содержанию эндогенной АБК в культивируемых in vitro каллусах пшеницы, в которых отмечалось значительное повышение содержание АБК в начале культивирования [5]. Это, повидимому, можно объяснить тем, что введение в культуру in vitro экспланта само по себе является, по мнению Р.Г. Бутенко [1], стрессовым воздействием, которое, возможно, и ведет к повышению уровня эндогенной АБК.

Введение же фрлуридона в среду для культивирования вызывало почти двукратное по сравнению с контролем снижение уровня АБК в каллусах через 1-ю неделю культивирования in vitro, и почти трехкратное снижение к 4-й неделе по сравнению с 1-й. На фоне пониженного содержания АБК, в каллусах AZ34 наблюдалось повышенное, по сравнению со Steptoe, содержание ИУК как на среде без фрлуридона, так и на среде с его добавлением (рис. 1.). Особенно заметной эта разница была на 4-й неделе культивирования in vitro.

Пара АБК/ауксины зачастую рассматривается с точки зрения их антагонистического взаимодействия [7], которая подтверждается и полученными нами данными. Возможно, что повышение уровня ауксинов на фоне снижения содержания АБК в каллусе может быть следствием снижения способности АБК влиять на уровень ауксинов путем активации процесса их конъюгирования [16]. Кроме того, возможно и обратное влияние ИУК на уровень АБК в каллусе вследствие способности ауксинов влиять на метаболизм АБК [10]. Следует отметить, что влияние АБК на ауксины в условиях культуры in vitro может быть двойственным, поскольку показана способность этого гормона не только активировать конъюигирование ауксинов, но и стимулировать их синтез [16]. Вероятно, характер действия АБК на метаболизм ауксинов может меняться на разных стадиях культивирования in vitro.

Гистологический анализ показал, что в каллусах Steptoe на среде MC без фрлуридона наблюдалось образование поверхностной меристематической зоны, из клеток которой формировались зародышеподобные структуры - эмбриоиды, имеющие типичное для зародышей злаков строение (рис. 2a). В каллусах же AZ34 также отмечалось фрормирование поверхностной меристематической зоны и начиналось образование эмбриоидов с диффреренцированными апикальной и базальной частями (рис. 2в). Однако дальнейшее развитие эмбриоидов у AZ34 задерживалось. При добавлении в среду фрлуридона у Steptoe наблюдалась задержка развития эмбриоидов на стадии становления апикально-базальной оси (рис. 2б), а в каллусах AZ34 инициировался только такой путь морфогенеза in vitro, как ризогенез (рис. 2г). 


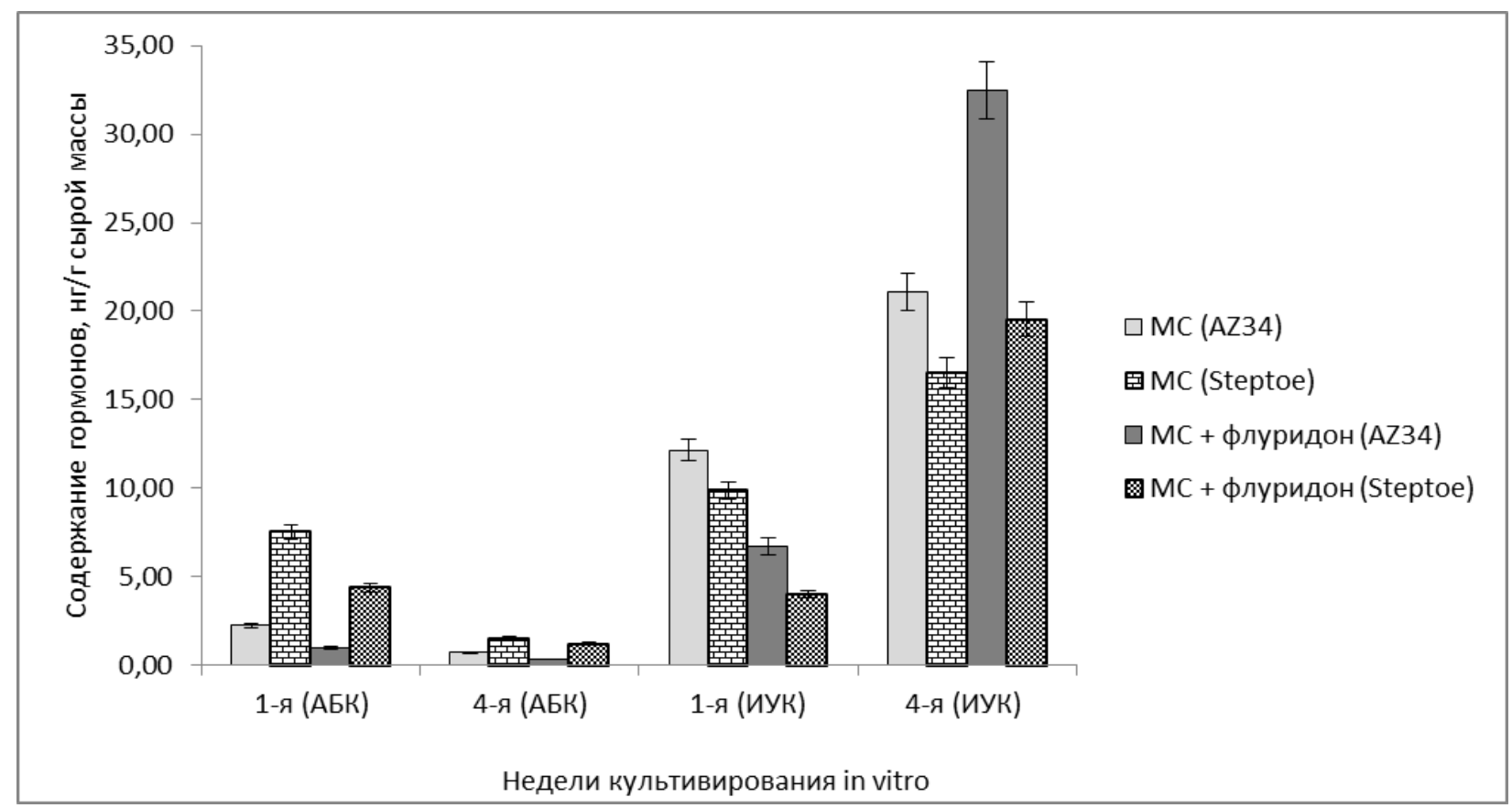

Рис. 1.Содержание эндогенных ИУК и АБК в каллусах ячменя через 1 и 4 недели культивирования in vitro, нг/г сырой массы

Хорошо известно, что именно ауксины играют важную роль в процессах роста и развития. Также известно, что для нормальной индукции и развития эмбриоидов in vitro необходимо снижение уровня эндогенных ауксинов [25], а также наличие адекватной концентрации эндогенной АБК $[4,18]$. Возможно, что избыточное количество эндогенной ИУК и недостаточное количество эндогенной АБК и обуславливают в нашем случае задержку развития эмбриоидов в каллусах Steptoe, обработанных фрлуридоном.

В каллусах AZ34, обработанных фрлуридоном индукция эмбриоидогенеза in vitro полностью блокировалась и реализовывался такой путь морфогенеза in vitro, как ризогенез. Способность ауксинов индуцировать ризогенез в каллусных культурах in vitro хорошо изучена, начиная с работы Скуга и Миллера [22; см. также:12, 27 и мн. др.]. Вполне закономерно, что повышенное содержание ИУК в каллусах AZ34 на фоне пониженного содержания АБК ведет к реализации такого пути, как ризогенез in vitro.

Таким образом, как генетически детерминированный низкий уровень АБК у AZ34, так и снижение содержания АБК под влиянием фрлуридона у обоих генотипов, а также вызванное этим повышение уровня ИУК приводило к блокировке или задержке развития эмбриоидов in vitro в каллусах ячменя. 


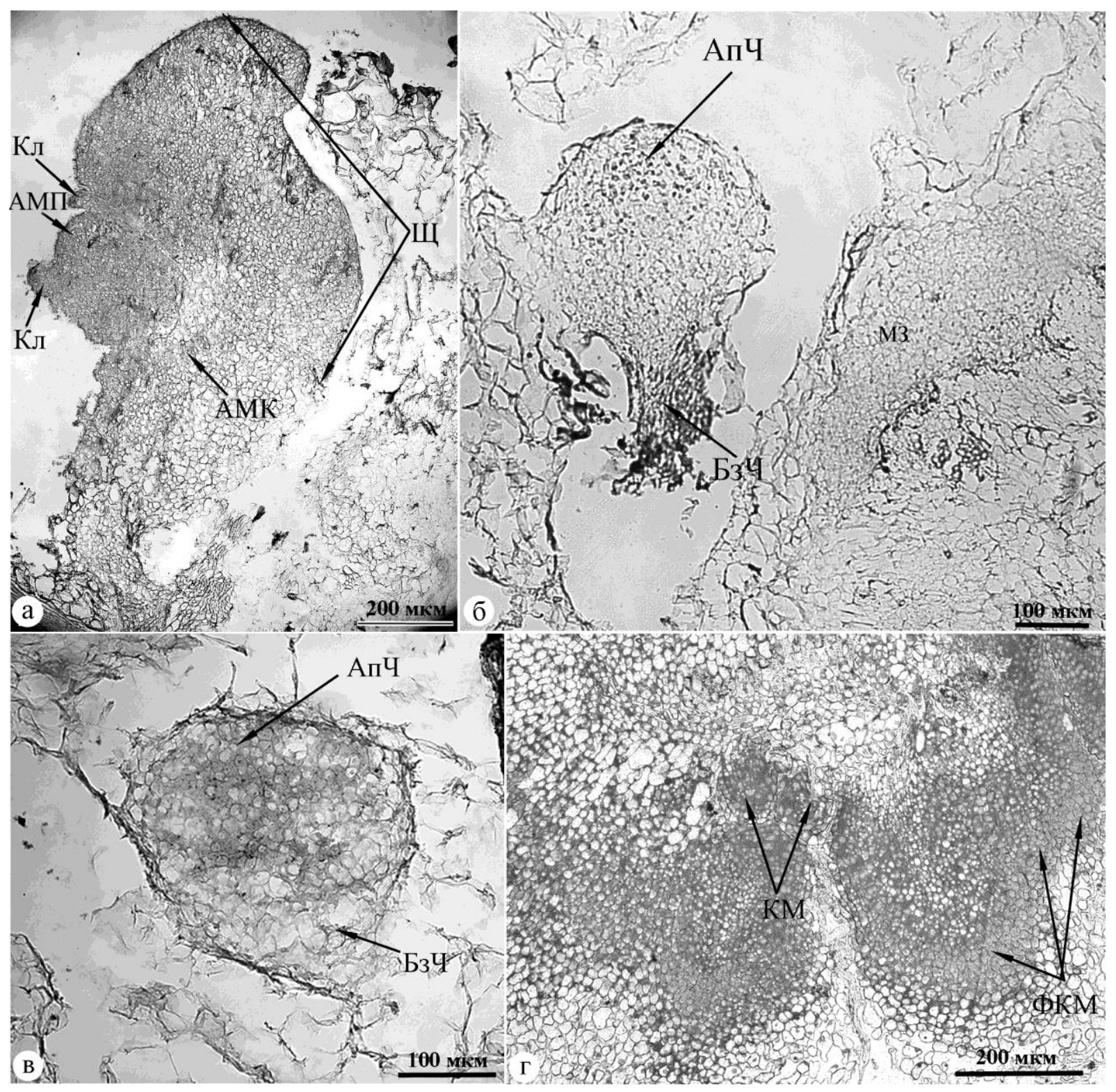

Рис. 2. Пути морфогенеза in vitro в каллусах ячменя сорта Steptoe $(\mathrm{a}$, б) и АБКдефицитного мутанта AZ34 (в, г) на среде MC (а, в) и среде MC, дополненной фрлуридоном (б, г): а - эмбриоид нормального строения на среде МС, б, в - задержка развития эмбриоида со сформированной апикально-базальной осью, г- ризогенез.

Полученные нами данные согласуются с результатами [9], показавшими полное блокирование развития эмбриоидов в каллусах древовидного папоротника Cyathea delgadii Sternb. в присутствии фрлуридона за счет отсутствия специфических паттернов делений клеток, необходимых для образования эмбриоидов. Похожие результаты были получены в работе [24], где опыты с применением флуридона показали, что АБК необходима не только для стимулирования созревания и нормального развития эмбриоидов, но также и для приобретения каллусами эмбриоидогенной компетентности.

По-видимому, полученные данные о положительной роли АБК совместно с другими гормонами в индукции и процессах соматического эмбриоидогенеза in vitro нужно расценивать как проявление хорошо установленного взаимодействия в многокомпонент- 
ной гормональной системе растений in vivo [обзор: 4]. Следует отметить, что вопрос совместного действия АБК и других веществ активно изучается, однако на уровне констатации эмпирических данных.

В то же время, способность фритогормонов влиять на концентрацию друг друга - одна из важных особенностей гормональной системы растений. Хотя эта закономерность не вызывает сомнений, имеющиеся данные о взаимодействии гормонов в процессе эмбриоидогенеза in vitro злаков весьма противоречивы и малочисленны, и для решения этого вопроса требуются дальнейшие исследования.

Работа выполнена в рамках государственного задания Минобрнауки России № 07500326-19-00 по теме № AAAA-A18-118022190099-6.

\section{Литература}

1. Бутенко Р.Г. Биология клеток высших растений in vitro и биотехнологии на их основе. М.: ФБК-ПРЕСС, 1999. 152 с.

2. Круглова Н.Н., Сельдимирова О.А. Регенерация пшеницы in vitro и ex vitro: цитогистологические аспекты. Уфра: «Гилем», 2011. 124 с.

3. Круглова Н.Н., Егорова О.В., Сельдимирова О.А., Зайцев Д.Ю., Зинатуллина А.Е. Световой микроскоп как инструмент в биотехнологии растений. Уфа: Гилем, Башк. энцикл., 2013. 128 с.

4. Круглова Н.Н., Сельдимирова О.А., Зинатуллина А.Е., Веселов Д.С. Абсцизовая кислота в системах культуры in vitro эксплантов // Известия Уфимского НЦ РАН. 20186. № 2. C.55-60.

5. Сельдимирова О.А., Безрукова М.В., Галин И.Р., Лубянова А.Р., Шакирова Ф.М., Круглова Н.Н. Влияние 24-эпибрассинолида на формирование, ростовые показатели и регенерационную способность каллусов in vitro контрастных по засухоустойчивости сортов пшеницы // Физиология растений. 2017. Т. 64. № 6. С. 461-472.

6. Сельдимирова О.А., Кудоярова Г.Р., Галин И.Р., Веселов Д.С., Круглова Н.Н. Влияние ингибиторов синтеза АБК и транспорта ауксинов на морфоргенез в культуре in vitro и активность пероксидаз у дефицитного по АБК мутанта ячменя и его исходного генотипа // Биомика. 2019. Т.11. № 4. С. 386-393.

7. Du H., Wu N., Fu J., Wang S., Li X., Xiao J., Xiong L A GH3 family member, OsGH3-2, modulates auxin and abscisic acid levels and differentially affects drought and cold tolerance in rice // J. of Exp. Bot. 2012. V. 63. № 18. P. 6467-6480.

8. Farias-Soares F.L., Steiner N., Schmidt E.C., Pereira M.L.T., Rogge-Renner G.D., Bouzon Z.L., Floh E.S.I., Guerra M.P. The transition of proembryogenic masses to somatic embryos in Araucaria angustifolia (Bertol.) Kuntze is related to the endogenous contents of IAA, ABA and polyamines // Acta Physiol. Plant. 2014. V. 36. № 7. P.1853-1865.

9. Grzyb M., Kalandyk F., Mikuła A. Efect of TIBA, furidone and salicylic acid on somatic embryogenesis and endogenous hormone and sugar contents in the tree fern Cyathea delgadii Sternb. // Acta Physiol. Plant. 2018. V. 40. № 1:1.

10. Hansen H., Grossmann K. Auxin-Induced Ethylene Triggers Abscisic Acid Biosynthesis and Growth Inhibition // Plant Physiol. 2000. V. 124. № 11. P. 1437-1448.

11. Joshi R., Kumar P. Regulation of somatic embryogenesis in crops: a review // Agri. Reviews. 2013. V. 34. № 1. P. 1-20. 
12. Ikeuchi M., Iwase A., Sugimoto K. Control of plant cell differentiation by histone modification and DNA methylation // Current opinion in plant biology. 2015. V. 28. № 9. P. 60-67.

13. In Vitro Embryogenesis in Higher Plants / Eds Germana M.A., Lambardi M. New York: Humana Press, 2016. 558 p.

14. Kruglova N.N., Titova G.E., Seldimirova O.A. Callusogenesis as an in vitro Morphogenesis Pathway in Cereals // Russ. J. Dev. Biol. 2018. V. 49. № 5. P. 245-249.

15. Loyola-Vargas V.M., Ochoa-Alejo N. Somatic Embryogenesis. An Overview // Somatic Embryogenesis: Fundamental Aspects and Applications / Eds Loyola-Vargas V., OchoaAlejo N. Springer, Cham, 2016. P. 1-8.

16. Park S.Y., Fung P., Nishimura N., Jensen D.R., Fujii H., Zhao Y., Lumba S., Santiago J., Rodrigues A., Chow T.F., Alfred S.E., Bonetta D., Finkelstein R., Provart N.J., Desveaux D., Rodriguez P.L., McCourt P., Zhu J.K., Schroeder J.I., Volkman B.F., Cutler S.R. Abscisic acid inhibits type $2 \mathrm{C}$ protein phosphatases via the PYR/PYL family of START proteins // Science. 2009. V. 324. № 5930. P. 1068-1071.

17. Plant Tissue Culture: An Introductory Text / Eds Bhojwani S.S., Dantu P.K. Springer India, 2013. P. 31-33.

18. Rai M.K., Shekhawat N.S., Harish, Gupta A.K., Phulwaria M., Ram K., Jaiswal U. The role of abscisic acid in plant tissue culture: a review of recent progress // Plant Cell Tiss. Org. Cult. 2011. V. 106. № 2. P.

19. Reis R.S., Vale E.M., Sousa K.R, Santa-Catarina C., Silveira V. Pretreatment free of 2,4dichlorophenoxyacetic acid improves the diferentiation of sugarcane somatic embryos by afecting the hormonal balance and the accumulation of reserves // Plant Cell Tiss. Org. Cult. 2021. V. 145. № 1. P. 101-115.

20. Ruduś I., Weiler E., Kępczynska E. Do stress-related phytohormones,.abscisic acid and jasmonic acid play a role in the regulation. of Medicago sativa L. somatic embryogenesis? // Plant Growth Regul. 2009. V. 59. № 2. P. 159-169.

21. Seldimirova O.A., Kudoyarova G.R., Kruglova N.N., Galin I.R., Veselov D.S. Somatic Embryogenesis in Wheat and Barley Calli in vitro Is Determined by the Level of Indoleacetic and Abscisic Acids // Russian Journal of Developmental Biology. 2019. V. 50. № 3. P. 124135.

22. Skoog F., Miller C.O. Chemical regulation of growth and organ formation in plant tissue cultured in vitro. Symp. Soc. Exp. Biol. 1957. V. 11. P. 118-131.

23. Somatic Embryogenesis: Fundamental Aspects and Applications / Eds Loyola-Vargas V., Ochoa-Alejo N. Cham: Springer, 2016. 506 p.

24. Su Y.H., Su Y.X., Liu Y.G., Zhang X.S. Abscisic acid is required for somatic embryo initiation through mediating spatial auxin response in Arabidopsis // Plant Growth Regul. 2013. V. 69. №. 2. P. 167-176.

25. Tang L.P., Zhang X.S., Su U.H. Regulation of cell reprogramming by auxin during somatic embryogenesis // aBIOTECH. 2020. V. 1. № 3. P. 185-193.

26. Vysotskaya L.B., Korobova A.V., Kudoyarova G.R. Abscisic acid accumulation in the roots of nutrient-limited plants: its impact on the differential growth of roots and shoots // J. Plant Physiol. 2008. V. 165. № 12. P.

27. Yu J., Liu W., Liu J., Qin P., Xu L. Auxin Control of Root Organogenesis from Callus in Tissue Culture // Front. Plant Sci. 2017. V.8: 1385. 